\title{
Relationship of sperm morphology assessed by strict criteria and outcome of artificial [intrauterine] insemination
}

\author{
Vedavathy Nayak $^{1 \%}$, Devika Gunasheela ${ }^{2}$ \\ ${ }^{1}$ Department of Obstetrics \& Gynecology, ESICMC \& PGIMSR, Bangalore, India \\ ${ }^{2}$ Medical Director, Gunasheela IVF Center, Basavangudi, Bangalore, India
}

Received: 2 January 2013

Revised: 29 January 2013

Accepted: 31 January 2013

\section{*Correspondence:}

Dr. Vedavathy Nayak

E-mail: vedavathynayak@yahoo.in

\begin{abstract}
Background: The aim of the study was to investigate the relationship between sperm morphology assessed by strict criteria and the outcome of artificial insemination.

Methods: 495 consecutive intrauterine insemination (IUI) cycles done for 417 couples in a 1-year period in Gunasheela IVF Center were studied. In all cases controlled ovarian stimulation and hCG timed IUI were performed. In all cases the inseminating motile sperm count after sperm preparation (at least one sample) was $20 \mathrm{million} / \mathrm{ml}$ and motility was $90 \%$ Grade A. Sperm morphology was assessed by strict criteria.

Results: Overall the pregnancy rates were significantly higher in cases with $\geq 14 \%$ normal morphology (23\%) and in cases with 10-13\% normal morphology (14\%). This was in contrast to the pregnancy rates in cases with $<10 \%$ normal morphology group (8\%). Further follow up of the outcome of pregnancies between the $\geq 10 \%$ normal morphology and $<10 \%$ normal morphology groups did not show any increased loss of pregnancies/anomalies in the $<10 \%$ normal morphology group but this was not statistically significant as the number of pregnancies in the $<10 \%$ normal morphology group was very less (8 out of 87 ).

Conclusions: These results emphasize the significance of sperm morphology as a predictor of pregnancy outcome (esp. pregnancy rates) in the IUI outcome.
\end{abstract}

Keywords: Male Factor Infertility, Intrauterine Insemination, Sperm Morphology

\section{INTRODUCTION}

There is good evidence in favour of IUI as the best first line treatment and most cost effective procedure for mild to moderate male subfertility. It seems very difficult to identify individual semen parameters predicting the likelihood of pregnancy after IUI. The percentage of morphologically normal spermatozoa assessed by strict criteria is an important sperm parameter likely to influence the success of IUI. The aim of this study was to establish the influence of sperm morphology assessed by strict criteria on the success rate of IUI in order to determine limits below which the chances of IUI success are limited.

\section{METHODS}

During a period of 1 year from September 2010 to August 2011, 495 consecutive IUI cycles were performed for 417 couples. In 406 cycles, the husband's sperm was utilised whereas in 89 cycles, donor sperm was utilized due to severe male factor infertility. In all cases controlled ovarian stimulation and hCG timed insemination was done. All patients had an infertility work-up including ultrasound monitoring of folliculogenesis and hysterosalpingogram.

Semen samples were collected by masturbation in a plastic container after an abstinence period of 3-5 days in the andrology lab. Semen samples were analysed after complete liquefaction according to the WHO guidelines. Sperm morphology was assessed using the strict criteria described by Kruger et al. Spermatozoa were prepared by the conventional swim up technique. In all patients the 
insemination motile sperm count after sperm preparation (at least 1 sample) was $>20$ million and motility was $>90 \%$ Grade A. The pregnancy rates and outcome of pregnancies were assessed in the following categories of normal sperm morphologies: $\leq 5 \%, 6-9 \%, 10-13 \%$ and $\geq 14 \%$.

\section{RESULTS}

Overall, during the period considered, 495 IUI cycles were analysed. A total of 87 patients became pregnant (Table 1).

Table 1: Percentage of pregnancies per IUI cycle.

\begin{tabular}{|llll|}
\hline IUIs & Number & Positives & Percentage \\
\hline AIH & 406 & 71 & 17.5 \\
\hline AID & 89 & 16 & 17.9 \\
\hline Total & 495 & 87 & 17.6 \\
\hline
\end{tabular}

The pregnancy rates in the different categories of normal sperm morphologies were as analysed (Table 2).

Table 2: Pregnancies in different categories of sperm morphologies.

\begin{tabular}{|llll|}
\hline $\begin{array}{l}\text { Normal } \\
\text { Forms }(\%)\end{array}$ & $\begin{array}{l}\text { No. of } \\
\text { IUI's }\end{array}$ & $\begin{array}{l}\text { No. of } \\
\text { pregnancies }\end{array}$ & $\begin{array}{l}\text { Pregnancy } \\
\text { rate }\end{array}$ \\
\hline$\leq 5 \%$ & 29 & 2 & $6 \%$ \\
\hline $6-9 \%$ & 70 & 6 & $8.6 \%$ \\
\hline $10-13 \%$ & 139 & 20 & $14.4 \%$ \\
\hline$\geq 14 \%$ & 257 & 59 & $23 \%$ \\
\hline
\end{tabular}

The overall outcome of IUI's is as shown below (Figure $1)$.

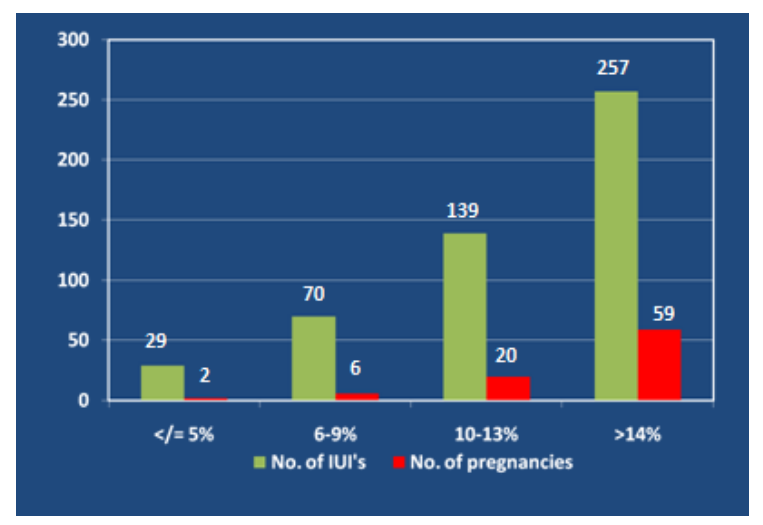

Figure 1: Outcome of IUIs.

Follow up of pregnancies in the $<10 \%$ normal morphology and the $\geq 10 \%$ normal morphology groups showed the following outcomes (Table 3 ).
Table 3: Outcome of pregnancies based on sperm morphology.

\begin{tabular}{|lll|}
\hline Outcome & $\begin{array}{l}<\mathbf{1 0 \%} \text { normal } \\
\text { morphology }\end{array}$ & $\geq \mathbf{1 0 \%}$ \\
\hline Live births & 2 & 9 \\
\hline $\begin{array}{l}\text { Follow up upto } 12 \text { wks. \& } \\
\text { ongoing }\end{array}$ & 4 & 54 \\
\hline $\begin{array}{l}\text { Missed abortions /Early } \\
\text { embryonic demise }\end{array}$ & 0 & 4 \\
\hline Biochemical pregnancies & 1 & 3 \\
\hline MTP conjoined twins & - & 1 \\
\hline Lost for follow up & 1 & 7 \\
\hline Ectopic pregnancy & - & 1 \\
\hline Total & 8 & 79 \\
\hline
\end{tabular}

The miscarriage rate was $8.8 \%$ in the $<10 \%$ normal morphology group and $12.5 \%$ in the $\geq 10 \%$ normal morphology group, but this was not significant as the number of pregnancies in the $<10 \%$ normal morphology group was very small (8 out of 87 ).

\section{DISCUSSION}

Intrauterine insemination is usually performed to overcome mild to moderate male factor infertility, as well as to increase the chances of conception in other cases of infertility. ${ }^{1}$ The sperm parameters which can be used to predict successful IUI outcome are controversial. ${ }^{2}$ The minimal recommended proportion of normal sperm morphology varies from $14 \%$ (Kruger's criteria) to $4 \%$ (WHO reference value: 5 th edn). ${ }^{3}$ In this study, we tried to investigate the importance of sperm morphology to predict the success rates and outcome in an intrauterine insemination programme. Sperm morphology turned out to be a good predictive parameter (i.e. $<10 \%$ normal forms $=$ poor pregnancy rates). When sperm morphology in semen analysis is very low $(<5 \%)$, it is better to recommend invitro fertilisation (IVF) and intracytoplasmic sperm injection (ICSI) to the couple rather than IUI. These findings are similar to a study by Lee et al (2002) who concluded that the success rate of IUI was highest when $14 \%$ or more of the sperm had normal morphology, was intermediate with values between $4 \%$ and $14 \%$, and was generally poor when fewer than $4 \%$ of the sperm was normal. ${ }^{4}$ Lindheim et al (1998) also found a very low pregnancy rate (1\% per cycle) when the sperm morphology score was $<4 \%{ }^{5}$ However another study did not find any substantial difference in the success of intrauterine insemination when normal sperm morphology in semen analysis is more than $20 \%$ compared to when it is less than $20 \%{ }^{6}$ Though there did not appear to be an increased incidence of miscarriage in the $<10 \%$ sperm morphology group, 
further studies including a larger number of pregnancies is required.

\section{CONCLUSIONS}

There is a definite association between poor sperm morphology and decreased pregnancy rates. The pregnancy rate $(14 \%)$ in the $10-13 \%$ normal morphology group is acceptable. Considering that IUI is less invasive $\&$ is cost effective, it may be offered in 6-9\% normal morphology after counseling about poor outcome. It is better to recommend IVF/ICSI in the $<5 \%$ normal sperm morphology group. Larger study is needed to assess the outcome of pregnancies in the poor sperm morphology group.

\section{REFERENCES}

1. Speroff L, Fritz MA. Male infertility. In: Clinical Gynecologic Endocrinology and Infertility, $7^{\text {th }} \mathrm{Ed}$. Philadelphia: Lippincott Williams and Wilkins;2005:1135-73.
2. Badawy A, Elnashar A, Eltotongy M. Effect of sperm morphology and number on success of intrauterine insemination. Fertil Steril 2009;91:77781.

3. World Health Organization. WHO laboratory manual for the examination and processing of human semen, $5^{\text {th }}$ edition, 2010. WHO, Department of Reproductive Health and Research.

4. Lee RK, Hou JW, Ho HY, Hwu YM., Lin MH, Tsai $\mathrm{YC}$, et al. Sperm morphology analysis using strict criteria as a prognostic factor in intrauterine insemination. Int J Androl 2002;25:277-80.

5. Lindheim SR, Barad DH, Zinger M, Witt B, Amin $\mathrm{H}$, Cohen B, et al. Abnormal sperm morphology is highly predictive of pregnancy outcome during controlled ovarian hyperstimulation and intrauterine insemination. J Assist Reprod Genet 1996;13:56972.

6. Motazedian SH, Hamedi B, Zolghadri J, Moftahedi $\mathrm{KH}$, Asadi N. Outcome of IUI Based on Sperm Morphology in Cases of Unexplained and Male Factor Infertility. Shiraz E-Med J 2009;10(2).

DOI: 10.5455/2320-1770.ijrcog20130210

Cite this article as: Nayak V, Gunasheela D. Relationship of sperm morphology assessed by strict criteria and outcome of artificial [intrauterine] insemination. Int $\mathbf{J}$ Reprod Contracept Obstet Gynecol 2013;2:58-60. 